paediatricians improve UK child health outcomes? No. Br J Gen Pract 2020; DOI: https://doi. org/10.3399/bjgp20X709289.

3. Patel S, Hodgkinson T, Fowler R, et al. Integrating acute services for children and young people across primary and secondary care. Br J Gen Pract 2020; DOI: https://doi.org/10.3399/bjgp20X708917.

\section{To ground or not to ground}

In addition to diagnosis and treatment, the GP must sometimes make a last-minute decision whether to allow a patient to travel or to ground them, causing the loss of their non-refundable airline ticket. The physician can become annoyingly hesitant in making the correct decision.

An 80-year-old woman, who had been my patient for the past 30 years, had reserved a flight to France on Sunday at $8.00 \mathrm{am}$. She came to my clinic on Friday evening with a typical glossopharyngeal neuralgia, in a panicky state, and afraid to lose her $\$ 800$ ticket should she be unable to travel on Sunday. She had been to an otolaryngologist who had found nothing wrong with her physically and had asked for an MRI of the brain, charging her $\$ 100$. She said she could not spend more, and I assured her that I would not charge her.

I started her on carbamazepine $200 \mathrm{mg}$ b.i.d. She called me on Saturday morning when I was at our summer home $60 \mathrm{~km}$ away, thanking and praising me for the 'miraculous' disappearance of her pain and her regained hope of travelling next morning. In the evening she called me again saying she had developed severe dizziness from the carbamazepine, and that her sons waiting in France had checked on the internet and told her that carbamazepine was for epilepsy. I explained to her that it was also the best drug for her neuralgia.

I told her to skip the next dose and also the Sunday morning dose, rest for the night, and ask for a wheelchair at the airport (which she had originally done already). I assured her that the side effect of the drug would be gone by the morning.

There was no further communication from her, nor from her sons in France, nor from her daughter in Australia after that evening call. My sleep was disturbed for two nights, not knowing whether she had made it to the airport, or had missed the flight and lost $\$ 800$, or, worse, had gone to the emergency room.

On Tuesday morning, having come back to Beirut, I passed by her building and rang the interphone. There was no answer, and I was relieved. But could she be at the hospital instead of in France? Fortunately, the concierge was around and told me he had helped her to the taxi that took her to the airport.

\section{Boghos I Artinian, \\ Lebanese Order of Physicians, Beirut, Lebanon. \\ Email: artiniandzoho.com}

DOI: https://doi.org/10.3399/bjgp20X710045

\section{Chronic non- communicable diseases: a sacrifice on the altar of COVID-19?}

Recently the United Nations Secretary General António Guterres characterised the COVID-19 healthcare crisis as the most challenging the humanity has faced since World War Two. In line with primary care's strategic role in responding to health disasters effectively, ${ }^{2}$ most of its human and material resources have been allocated in fighting this outbreak, postponing or even disregarding other patients' needs, including the prevention and management of chronic non-communicable diseases. To make things worse, patients may even avoid attending primary care appointments for fear of catching COVID-19.

Prevention and management of chronic non-communicable diseases are important to mitigate the risk of both morbidity and avoidable mortality, and limit severe acute and chronic complications; the latter may include cardiovascular disease, blindness, end-stage renal disease, and lower-limb amputation. Additionally, community-dwelling subjects harbouring underlying chronic non-communicable diseases, including cardiovascular disease, hypertension, diabetes mellitus, and chronic lung disease, carry an increased risk of adverse COVID-19 outcomes. ${ }^{3}$ Therefore, a major concern is that the suspension of prevention and caring for chronic disease could elicit a deterioration of the global health status and a steep rise in hospital admissions and related healthcare costs, which may in turn overburden health systems and surpass their surge capacity.

The current shift from on-site to remote consultations might balance the need for maintaining continuity of care while containing COVID-19. However, reverting to virtual consultations may prove not only technically, logistically, and regulatorily challenging, but also clinically risky and ineffective for some patients. ${ }^{4}$ Therefore, selection of candidate patients should be subject to a meticulous patient-centred risk-benefit assessment. Individuals unsuitable for remote consultations should be prompted to attend in person, after properly managing their worries over COVID19 transmission. In case these cannot be effectively addressed, the alternative of a home visit may be contemplated, especially in high-risk individuals or patients with chronic mental disease, where sustaining continuity of care needs to be prioritised. Proactive strategies are necessary to maximise patient adherence to regular follow-up and minimise their anxiety or fears. Policymakers are urged to secure adequate human and material resources for chronic disease care, and ensure its uninterrupted provision.

Philippe Domeyer,

School of Social Sciences, Hellenic Open University, Patra, Greece.

Email: ph.domeyerlaac.eap.gr

Vasiliki Katsari,

Department of Hygiene, Epidemiology and Medical Statistics, Medical School, National University of Athens, Greece.

Anargiros Mariolis,

Health Center of Areopolis, Greece.

\section{REFERENCES}

1. Guterres A. Transcript of UN Secretary-General's virtual press encounter to launch the Report on the Socio-Economic Impacts of COVID-19 https://www.un.org/sg/en/content/sg/pressencounter/2020-03-31/transcript-of-un-secretarygeneral\%E2\%80\%99s-virtual-press-encounterlaunch-the-report-the-socio-economic-impactsof-covid-19 (accessed 7 May 2020).

2. Redwood-Campbell L, Abrahams J. Primary health care and disasters - the current state of the literature: what we know, gaps and next steps. Prehosp Disaster Med 2011; 26(3): 184-191.

3. Yang J, Zheng Y, Gou X, et al. Prevalence of comorbidities and its effects in coronavirus disease 2019 patients: a systematic review and metaanalysis. Int J Infect Dis 2020; DOI: https://doi. org/10.1016/j.jijid.2020.03.017.

4. Shaw S, Wherton J, Vijayaraghavan S, et al. Advantages and limitations of virtual online consultations in a NHS acute trust: the VOCAL mixed-methods study. Health Services and Delivery Research 2018; 6(21).

DOI: https://doi.org/10.3399/bjgp20X710057 